The Journal of Laryngology \& Otology

http://journals.cambridge.org/JLO

Additional services for The Journal of Laryngology \& Otology:

Email alerts: $\underline{\text { Click here }}$

Subscriptions: $\underline{\text { Click here }}$

Commercial reprints: $\underline{\text { Click here }}$

Terms of use : $\underline{\text { Click here }}$

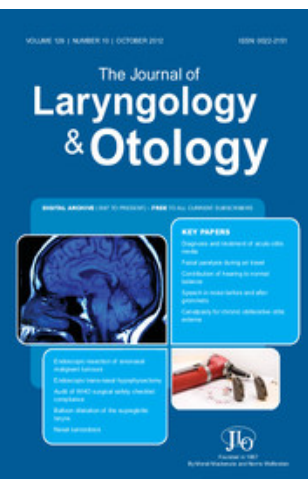

\title{
Temporomandibular joint capsule prolapse: a technique of repair using autograft cartilage
}

Shakeel R. Saeed, Nadeem R. Saeed and Gerald B. Brookes

The Journal of Laryngology \& Otology / Volume 108 / Issue 01 / January 1994, pp 30 - 32

DOI: 10.1017/S0022215100125757, Published online: 29 June 2007

Link to this article: http://journals.cambridge.org/abstract_S0022215100125757

How to cite this article:

Shakeel R. Saeed, Nadeem R. Saeed and Gerald B. Brookes (1994). Temporomandibular joint capsule prolapse: a technique of repair using autograft cartilage. The Journal of Laryngology \& Otology, 108, pp 30-32 doi:10.1017/ S0022215100125757

Request Permissions : $\underline{\text { Click here }}$ 


\title{
Temporomandibular joint capsule prolapse: a technique of repair using autograft cartilage
}

\author{
Shakeel R. SAeEd, F.R.C.S., Nadeem R. SAeed, F.D.S.R.C.S.*, Gerald B. Brookes, F.R.C.S.
}

\begin{abstract}
Loss of bony integrity of the temporomandibular joint may result in prolapse of the joint capsule into the external auditory canal. This in turn gives rise to arthralgia, trismus and earache and a risk of septic arthritis.

We describe a technique of repair which is simple, uses autologous tissue and has an acceptable cosmetic and functional result.
\end{abstract}

Key words: Temporomandibular joint; Prolapse; Cartilage; Transplantation, autologous

\begin{abstract}
Introduction
Bony dehiscence of the anterior external meatus, whilst rare, may be due to local invasion by primary external canal tumours, infective processes and trauma to the mandibular condyle. Since the advent of antimicrobial treatment, particularly for chronic granulomatous infections such as tuberculosis, destructive temporomandibular joint sepsis has become uncommon though reactive arthritis, with atypical mycobacteria, has been observed (Maricic and Alepa, 1990). Reports of otitis externa complicated by fistula formation between canal and joint (Dingle, 1992) or secondary septic arthritis are sporadic (Thomson, 1989). Posterior dislocation of the temporomandibular joint with auditory canal injury is rare but documented (Helmy, 1957; Loh et al., 1991), as is spontaneous herniation of the joint into the ear canal (Hawke et al., 1987).

Surgery for meatal stenosis carries the risk of loss of bone of the anterior canal wall by excessive removal during meatoplasty or breakdown if there is infection complicating the procedure. If the dehiscence is large enough posterior prolapse of the temporomandibular joint capsule into the external auditory meatus may occur resulting in pain, masticatory difficulty and trismus as well as the potential risk of recurrent infective arthritis. We describe such a case and a simple technique aimed at restoring the integrity of the posterior joint wall.
\end{abstract}

\section{Case report}

A 59-year-old health visitor with a long history of bilateral chronic suppurative otitis media presented for a second opinion regarding possible further management of hearing impairment. She had undergone a right cortical mastoidectomy in her youth with a resultant dry but poor hearing ear. More recently, following an acute upper respiratory tract infection she had developed left otorrhoea, which on subsidizing with topical antibiotics, left her with a safe posterio-inferior perforation of the drumhead.

Examination of the right ear showed a smooth, skinlined, acquired meatal atresia which was clean and dry. Audiometrically the left ear showed a predominantly sensorineural low frequency hearing loss with average masked bone conduction thresholds at $35 \mathrm{~dB}$. On the right there was a $30 \mathrm{~dB}$ air-bone gap with air conduction thresholds on average at $55 \mathrm{~dB}$. Computerized tomography of the right petrous temporal bone confirmed an aircontaining middle ear cleft and signs of a previous cortical mastoidectomy. There was however a soft tissue obstruction in the external meatus, lateral to the normal looking tympanic membrane. On the basis of these findings the patient underwent excision of the canal stenosis with splitskin grafting to the denuded meatal areas. Her post-operative course was uneventful and audiometry at three months confirmed complete closure of the air-bone gap.

Two months later the right ear began to discharge and Pseudomonas aeruginosa was cultured from the pus. This was treated with topical antibiotic ear drops, but despite repeated microsuction, dressings, cautery to granulations and systemic antibiotics, it became clear that the anterior bony canal wall had been eroded allowing a prolapse of the temporomandibular joint capsule into the external meatus with mandibular movements. This led to marked difficulty in chewing, arthralgia and trismus as well as persistent otorrhoea. The patient suffered a particularly painful and unpleasant episode of septic temporomandibular joint arthritis which settled completely with systemic antibiotic treatment. Reconstructive surgery was undertaken seven months after the original meatal stenosis excision.

\section{Operative details}

The procedure was undertaken under general anaes- 


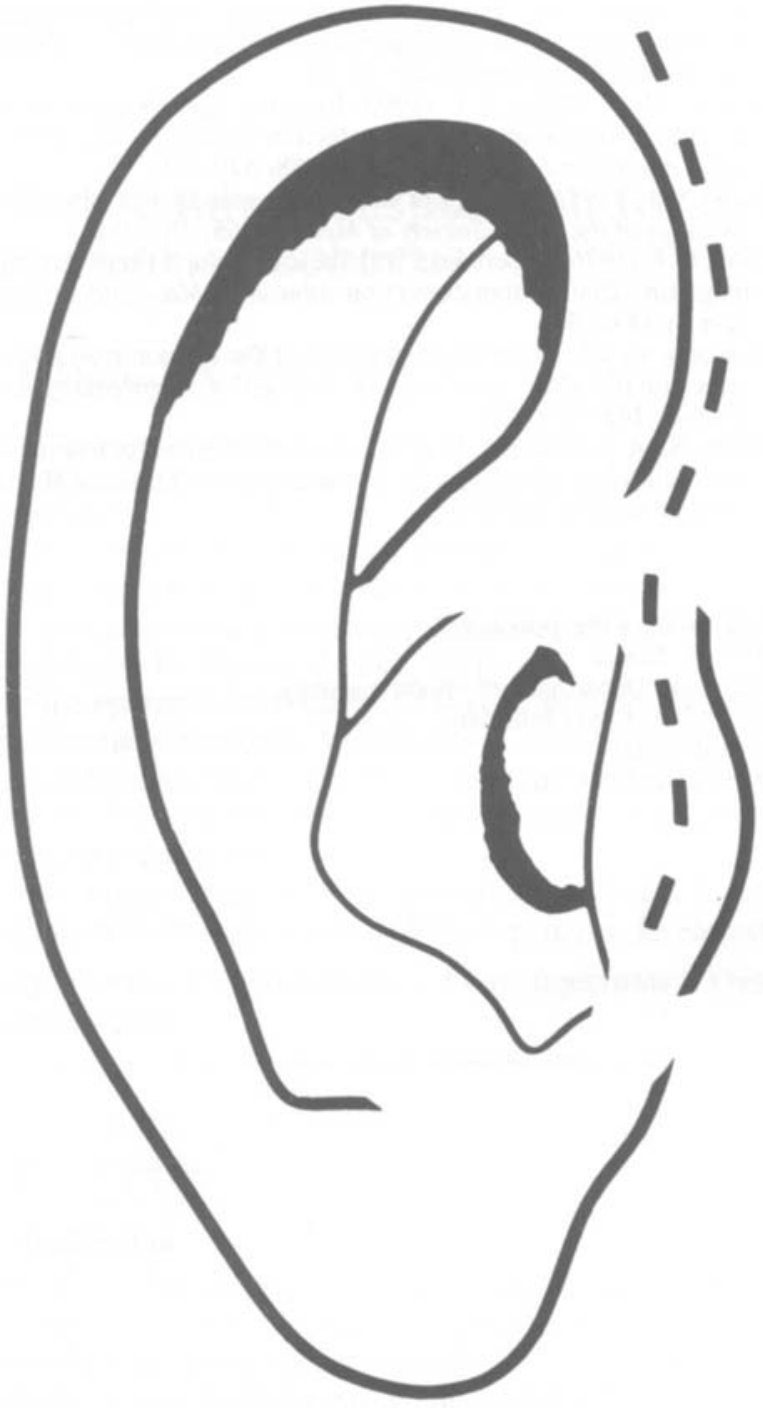

FIG. 1

Extension of the endaural incision onto the medial surface of the tragus.

thesia using a cuffed endotracheal tube. A bolus dose of cefuroxime $750 \mathrm{mg}$ was administered intravenously.

After standard preparation of the operative site an endaural incision was made, extending posterior to the tragus and at the cartilagenous-bony junction to the level of the floor of the external meatus (Figure 1). This incision was developed in the subperichondrial plane allowing delivery of the whole tragal cartilage. The plane was then developed medially to reveal a 9 by $6 \mathrm{~mm}$ deficit in the bony external meatus with temporomandibular joint capsule prolapsing through the dehiscence. The bony margins of the dehiscence were superficially osteitic.

The intact meatal skin was elevated freely and the harvested tragal cartilage positioned anterior to the bony deficit, i.e. between the bony meatal wall and the joint capsule as an 'underlay' graft (Figure 2). The denuded areas in the meatus were covered with a split-skin graft. The canal was dressed with gelfoam, two otowicks medially and a bismuth-iodine paste dressing laterally. The skin incision was closed with interrupted nylon sutures and a pressure dressing applied, the skin graft donor site having been dressed with tulle-gras and a light bandage. The patient was covered with intravenous cefuroxime 48 hours post- operatively at which point the pressure dressing was removed and the patient discharged.

\section{Results}

Ten days post-operatively the ear canal packing and skin sutures were removed with replacement of the otowicks. The arthralgia and mild trismus persisted for eight days but subsided rapidly after that. On review at four weeks there was slight granularity of the anterior canal wall which was managed with antibiotic ear drops. This granularity may well have represented healing and subsequent epithelization by secondary intention as the splitskin graft had been laid on what amounted to a nonvascular bed.

Two months after the operation the canal wall had healed with no associated stenosis or dehiscence. Significantly the trismus, arthralgia and difficulty in chewing had abated completely and the hearing threshold had recovered to its previously excellent post-stenosis excision level.

\section{Discussion}

The case described illustrates the potential problems of a bony meatoplasty which is complicated by a secondary infection. Despite repeated local toilet and the use of longterm antibiotics to control the osteitis of the anterior canal wall the patient experienced marked difficulty related to the loss of temporomandibular joint integrity.

The technique of joint reconstruction with cartilage has the advantage of using autologous tissue harvested from the same incision used to effect the repair, with acceptable cosmesis. The incision itself represents a modification of the standard preauricular approach to the temporomandibular joint, which, together with the submandibular incision represent the two most favoured means of access to the joint (Rowe, 1972).

The work of Sailer, twenty years ago showed that lyophilized bank cartilage can be successfully used to reconstruct facial contours, with tissue resorption of between 10

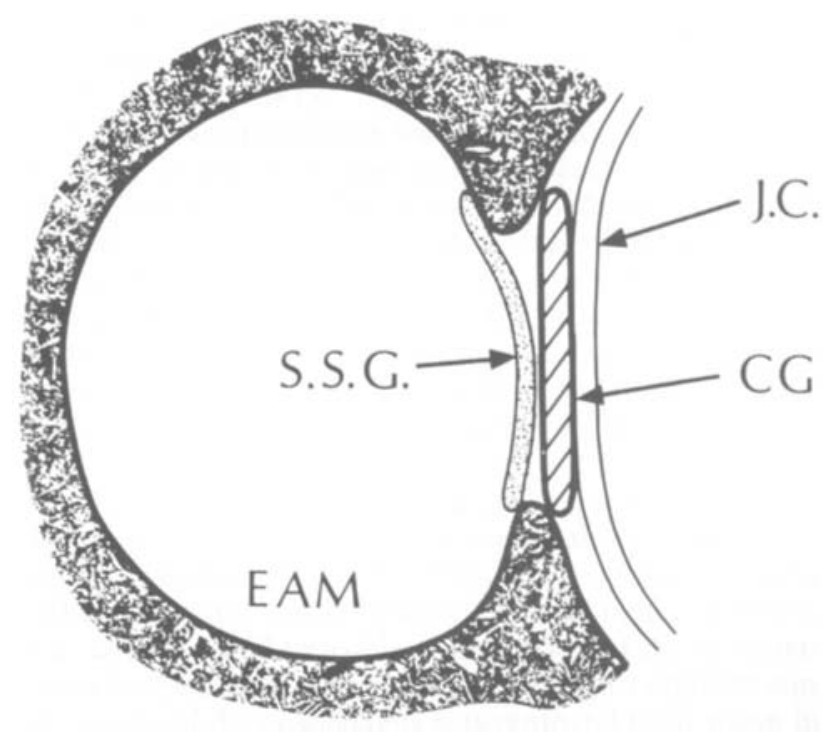

FIG. 2

Schematic diagram to show the position of the cartilage graft. $\mathrm{EAM}=$ external auditory meatus; $\mathrm{CG}=$ cartilage graft $;$ J.C. $=$ joint capsule; S.S.G. = split-skin graft. 
and 20 per cent, a figure comparable to autologous tissue resorption rates (Sailer, 1976). Conversely, alloplastic implants may lead to infection and extrusion whilst bone grafts undergo marked resorption when in the post-condylar region (Whear and Langdon, 1991). The final functional outcome in our technique substantiates the anatomical principles behind the procedure.

\section{Acknowledgement}

We are grateful to the Department of Medical Illustration at the Royal National Throat, Nose and Ear Hospital for their help in preparing the line drawings.

\section{References}

Dingle, A. F. (1992) Fistula between the external auditory canal and the temporomandibular joint: a rare complication of otitis externa. Journal of Laryngology and Otology 106: 994-995.

Hawke, M., Kwok, P., Mehta, M. (1987) Bilateral spontaneous temporomandibular joint herniation into the external auditory canal. Journal of Laryngology and Otology 16: 387-389.

Helmy, M. (1957) Rare type of dislocation of the temporomandibular joint. Egyptian Dental Journal 3: 27.
Loh, F., Tan, K. B. C., Tan, K. (1991) Auditory canal haemorrhage following mandibular condylar fracture. British Journal of Oral and Maxillofacial Surgery 29: 12-13.

Maricic, M. J., Alepa, F. P. (1990) Reactive arthritis after mycobacterium avium-intracellulare infection: Poncet's disease revisited. American Journal of Medicine 88: 549-550.

Rowe, N. L. (1972) Surgery of the temporomandibular joint. Proceedings of the Royal Society of Medicine 65: 383-388.

Sailer, H.F. (1976) Experiences with the use of lyophilized bank cartilage for facial contour correction. Journal of Maxillofacial Surgery 4: 149-157.

Thomson, H. G. (1989) Septic arthritis of the temporomandibular joint complicating otitis externa. Journal of Laryngology and Otology 103: 319-321.

Whear, N. M., Langdon, J. D. (1991) A simple method for fixation of post-condylar cartilage grafts. British Journal of Oral and Maxillofacial Surgery 29: 94-96.

Address for correspondence:

Mr S. R. Saeed,

University Department of Otolaryngology,

Manchester Royal Infirmary,

Oxford Road

Manchester M13 9WL. 